\title{
Essential Oil and Fatty Acid Composition of Centaurea solstitialis ssp. solstitialis
}

\section{Burcu SÜMER TÜZÜN", Tuba GÖNENÇ¹, Pelin TAŞTAN ${ }^{1}$, Tuğçe FAFAL ${ }^{1}$, Betül DEMIRCI'², Bijen KIVÇAK ${ }^{1}$}

\author{
${ }^{1}$ Department of Pharmacognosy, Faculty of Pharmacy, Ege University, Bornova, Izmir, Turkey \\ ${ }^{2}$ Department of Pharmacognosy, Faculty of Pharmacy, Anadolu University, Eskişehir, Turkey
}

Received: 30 April 2017 - Accepted: 06 July 2017

\begin{abstract}
Centaurea is a widespread genus from Asteraceae family in Turkey. There are plenty of researches about fatty acid and essential oil profiles of Centaurea species. Essential oils were obtained using a Clevenger apparatus by hydrodistillation from aerial part of the plant. The essential oil composition of the plant was identified by GC-MS using FID detector. 31 compounds representing 91.5\% were identified. Hexadecanoic acid (50.2\%) and tetradecanoic acid(10.1\%) were found to be the major compounds. For fatty acids, fatty acid methyl esters (FAMEs) were prepared. The fatty acid compositions were analyzed by GC. Saturated fatty acids (SFAs) were totally $25.05 \%$, monounsaturated fatty acids (MUFAs) were $19.60 \%$ and polyunsaturated fatty acids were $19.86 \%$. The major compounds were found as oleic acid (18.54\%), linoleic acid (10.07\%), palmitic acid (8.28\%), stearic acid $(6.82 \%)$ and $\gamma$ - linoleic acid $(6.75 \%)$.
\end{abstract}

Keywords: Centaurea, essential oil, fatty acid

\section{INTRODUCTION}

Asteraceae family which is included in Cynarae ordo comprises 4 sub-ordo; Carduinea, Carlineae, Centaureinae and Echinipsideae. Centaurea is included in Centaureinae. Asteraceae family has 130 genus in Turkey. Centaurea is a widespread genus including 180 species [1,2]. Centaurea genus is widely used in folk medicine as sedative, antipyretic and against allergy in Turkey. Centaurea solstitialis ssp. solstitialis is an also widespread species from this genus. According to the etnobotanic researches, $C$. solstitalis ssp. solstitialis is mostly used for urinary diseases [3]. When we examine the the general content of the species it is well known that sesquiterpene lactones, flavonoids and polyacetylenes are major groups of seconder metabolites [4-6].

Fatty acids have many important biological functions such as presenting in biological membran structure and being an energy source. PUFAs and MUFAs are useful for decreasing LDL [7]. Essential oils have also different biological activities such as antimicrobial and

\footnotetext{
${ }^{*}$ Corresponding Author E-mail: burcusmer@gmail.com
} 
antioxidant. There are lots of essential oil and fatty acid researches about different Centaurea species [8].

In this study we present the volatile oil profile and fatty acid content of $C$. solstitialis ssp. solstitalis. To the best of our knowledge, this is the first report for determining essential oil and fatty acid profile of Centaurea solstitialis ssp. solstitialis from Elazı̆̆, Turkey.

\section{MATERIAL and METHODS}

\subsection{Plant Material}

C. solstitalis ssp. solstitialis was collected from Elazı $\breve{g}$, Turkey in 2011. The plant was identified by one of the authors (B. Kivcak) from Ege University. Voucher specimen was deposited by number 1468 in the Herbarium of Faculty of Pharmacy, Department of Pharmacognosy, Ege University, Izmir, Turkey. The dried and powdered aerial parts of the plant material $(40 \mathrm{~g})$ have been extracted by petroleum ether $(400 \mathrm{ml})$ for $6 \mathrm{~h}$ at $60^{\circ} \mathrm{C}$ by Soxhlet extractor. The solvent was evaporated by a rotary evaporator. The obtained oil was esterified to determine the fatty acid composition. Additionally the air-dried aerial parts of the plant was subjected to hydrodistillation for $3 \mathrm{~h}$ using a Clevenger-type apparatus to obtain essential oil.

\subsection{Fatty acid methyl esters (FAMEs) preparation}

The fatty acids were esterified into methyl esters by saponification with methanol $(50 \%)$ containing $5 \%$ sodium hydroxide at $100{ }^{\circ} \mathrm{C}$ for $10 \mathrm{~min}$ and transesterified with $14 \%(\mathrm{v} / \mathrm{v})$ boron trifluoride $\left(\mathrm{BF}_{3}\right)$ in methanol $100{ }^{\circ} \mathrm{C}$ for $5 \min (\mathrm{A})$.

\subsection{GC Conditions}

Fatty acid methyl esters (FAMEs) were analyzed on a HP (Hewlett Packard) Agilent 6890 $\mathrm{N}$ model gas chromatograph (GC), equipped with a flame ionization detector (FID) and fitted to a Supelco SP-2380 Fased Silica capillary column $(60 \mathrm{~m}, 0.25 \mathrm{~mm}$ i.d. and $0.2 \mu \mathrm{m})$. Injector and detector temperatures were set at $250^{\circ} \mathrm{C}$ and $260^{\circ} \mathrm{C}$, respectively. The oven was programmed at an initial temperature of $140^{\circ} \mathrm{C}$ and an initial time of $5 \mathrm{~min}$. Thereafter the temperature was increased up to $240^{\circ} \mathrm{C}$ at a rate of $3^{\circ} \mathrm{C} \mathrm{min}^{-1}$. The total run time was $41.33 \mathrm{~min}$. Helium was used as the carrier gas $\left(1 \mathrm{ml} \mathrm{min}^{-1}\right)$. Identification of fatty acids was carried out by comparing sample FAME peaks from samples with standarts (26). The results were expressed as FID response area in the relative percentages. Each reported result is given as the average value of three $\mathrm{GC}$ analyses. The results are offered as means \pm S.D.

\subsection{Gas Chromatography-mass spectrometry (GC-MS) Conditions}

Agilent gas chromatograph model 6890 equipped with an Innowax FSC column (60 m x $0,25 \mathrm{~mm} \times 0,25 \mu \mathrm{m})$. Instrument conditions were programmed from $60^{\circ} \mathrm{C}(10 \mathrm{~min})$ to $220^{\circ} \mathrm{C}$ $\left(5^{\circ} \mathrm{C} / \mathrm{min}\right)$, stayed $10 \mathrm{~min}$ at $220^{\circ} \mathrm{C}$ and to $240^{\circ} \mathrm{C}$ for $1 \mathrm{~min}$. Split ratio was $40: 1$; injector and detector temperatures were 250 and $280^{\circ} \mathrm{C}$, respectively. The MS conditions were programmed as ionization potential at $70 \mathrm{eV}$, between 35-450 mass range. In order to identificate the components by comparison, their relative retention times and their relative retention indices (RRI) were used by analyzing Wiley GC/MS Library, Adams Library, MassFinder Library and in Baser Library. Retention indices were determined by using standard alkanes $\left(\mathrm{C}_{9}-\mathrm{C}_{30}\right)$ and also by comparison of literature data.

\section{RESULTS AND DISCUSSION}

The results of fatty acid analyses are shown in Table 1. Saturated fatty acids (SFAs) were totally $25.05 \%$, monounsaturated fatty acids (MUFAs) were $19.60 \%$ and polyunsaturated fatty acids were $19.86 \%$. The major compounds were found as C 18:1 $\omega 9$ (oleic acid) (18.54\%), C 18:2 
$\omega 6$ (linoleic acid) (10.07\%), C 16:0 (palmitic acid) (8.28\%), C 18:0 (stearic acid) (6.82\%) and C 18:3 $\omega 6$ ( $\gamma$ - linoleic acid) $(6.75 \%)$.

Table 1. Fatty Acid Profile of C. solstitialis ssp. Solstitialis

\begin{tabular}{|c|c|}
\hline Fatty Acids & Centaurea solstitialis ssp. solstitialis \\
\hline C 4:0 (Butyric acid) & - \\
\hline C 6:0 (Caproic acid) & - \\
\hline C 8:0 (Caprilic acid) & 1.76 \\
\hline C 12:0 (Lauric acid) & 2.87 \\
\hline C 13:0 (Tridecyclic acid) & - \\
\hline C 14:0 (Miristic acid) & 2.45 \\
\hline C 15:0 (Pentadecanoic acid) & 1.06 \\
\hline C 16:0 (Palmitic acid) & 8.28 \\
\hline C 17:0(Heptadecanoic acid) & - \\
\hline C 18:0 (Stearic acid) & 6.82 \\
\hline C 21:0(Heneicanoic acid) & 1.08 \\
\hline C 22:0 (Behenic acid) & - \\
\hline C 23:0 (Tricosanoic acid) & 0.56 \\
\hline C 24:0 (Lignoseric acid) & 0.17 \\
\hline$\sum \mathbf{S F A}^{\mathbf{b}}$ & 25.05 \\
\hline C $18: 1 \omega 9$ (Oleic acid) & 18.54 \\
\hline C 20:1 $\omega 9$ (Gondoic acid) & - \\
\hline C $24: 1 \omega 9$ (Nervonic acid) & 1.06 \\
\hline$\sum$ MUFA $^{\mathbf{b}}$ & 19.60 \\
\hline C 18:2 $\omega 6$ (Linoleic acid) & 10.07 \\
\hline C $18: 3 \omega 6$ ( $\gamma$-linolenic acid $)$ & 6.75 \\
\hline C20:303(Eicosotrienoic acid) & 3.04 \\
\hline$\sum$ PUFA $^{\mathbf{b}}$ & 19.86 \\
\hline
\end{tabular}

${ }^{a}$ n: 3; SFA: saturated fatty acids, MUFA: monounsaturated fatty acids,

PUFA: polyunsaturated fatty acids

The hydrodistillation of the aerial part of $C$. solstitialis ssp solstitialis gives essential oil of yellow colour. The identified components of essential oils and percentages are shown in Table 2. 31 compounds representing $91.5 \%$ were identified. Hexadecanoic acid $(50.2 \%)$ and tetradecanoic acid(10.1\%) were found to be the major compounds. 
Table 2. Identified Essential Oil Components from C. solstitalis ssp. solstitialis

\begin{tabular}{|c|c|c|}
\hline RRI & COMPOUND & PERCENTAGE (\%) \\
\hline 1400 & Nonanal & 0.3 \\
\hline 1705 & Zizanene & 0.3 \\
\hline 1740 & $\alpha$-Muurolene & 0.4 \\
\hline 1827 & $(E, E)$-2,4-Decadienal & 0.7 \\
\hline 1830 & Tridecanal & \\
\hline 1838 & (E)-p-Damascenone & 0.3 \\
\hline 1868 & (E)-Geranyl acetone & 0.3 \\
\hline 1870 & Hexanoic acid & 0.1 \\
\hline 1945 & 1,5-Epoxy-salvial(4)14-ene & 0.6 \\
\hline 1958 & $(E)-\beta$-Ionone & 0.6 \\
\hline 2008 & Caryophyllene oxide & 1.1 \\
\hline 2037 & Salvial-4(14)-en-1-one & 0.6 \\
\hline 2041 & Pentadecanal & 0.3 \\
\hline 2080 & Junenol (=Eudesm-4(15)-en-6-ol) & 0.5 \\
\hline 2084 & Octanoic acid & 0.6 \\
\hline 2098 & Globulol & 0.5 \\
\hline 2130 & Salviadienol & 0.3 \\
\hline 2131 & Hexahydrofarnesyl acetone & 1.0 \\
\hline 2144 & Spathulenol & 4.4 \\
\hline 2209 & T-Muurolol & 0.8 \\
\hline 2255 & $\alpha$-Cadinol & 1.1 \\
\hline 2278 & Torilenol & 0.9 \\
\hline 2300 & Tricosane & 1.1 \\
\hline 2369 & Eudesma-4(15),7-dien-4ß-ol & 1.0 \\
\hline 2500 & Pentacosane & 0.8 \\
\hline 2503 & Dodecanoic acid & 4.4 \\
\hline 2622 & Phytol & 2.7 \\
\hline 2670 & Tetradecanoic acid & 10.1 \\
\hline 2700 & Heptacosane & 2.5 \\
\hline 2822 & Pentadecanoic acid & 1.3 \\
\hline 2900 & Nonacosane & 0.7 \\
\hline \multirow[t]{2}{*}{2931} & Hexadecanoic acid & 51.2 \\
\hline & & 91.5 \\
\hline
\end{tabular}

In previous studies for fatty acid profile; $\mathrm{C}$ 18:2 $\omega 6$ (linoleic acid) and $\alpha$-linoleic acid seemed to be the major compoud and C 18:1 $\omega 9$ (oleic acid) and C 16:0 (palmitic acid) are also predominantly major compounds. Our results are compatible with literature about fatty acid profile of Centaurea species. Oleic acid; monounsaturated fatty acid (MUFA) is the major compound of our research and this result can show that $C$. solstitialis ssp. solstitialis can be beneficial for decreasing LDL [7, 9].

According to the literature an essential oil research about $C$. solstitialis from Iran showed different profile than our research about $C$. solstitialis ssp. solstitialis. In that research hexadecanoic acid was also found to be a major (30.8\%) compound with a different amount and caryophyllene oxide (25.2\%) was also a major compound [10]. This difference may be because of the region or the variation of subspecies. Additionally other researches of essential 
oil composition of Centaurea species showed; caryophyllene oxide, spathulenol, tetracosane, arachidic acid, hexadecanoic acid, isononane and tetradecanoic acid were mostly found major compounds. Consequently our results are compatible with other Centaurea species $[11,12]$.

\section{Conflict of Interests}

Authors declare that there is no conflict of interests.

\section{REFERENCES}

[1] Davis PH. (1975) Flora of Turkey. Edinburgh: 484-585.

[2] Davis PH. (1984) Flora of Turkey. Edinburgh:166-8.

[3] Çakılcığlu U., Türkoğlu İ., Kurşat M. (2007) Harput (Elazı̆̆) ve çevresindeki bazı bitkilerin etnobotanik özellikleri, Doğu Anadolu Bölgesi Araştırmaları,5: 22-8.

[4] Gülcemal D., Alankuş-Çalışkan O., Karaalp C., Ors A.U., Ballar P., Bedir E. (2010) Phenolic Glycosides with antiproteasomal activity from Centaurea urvillei DC. subsp. urvillei, Carbohydrate Researchs, 345: 2529-33.

[5] Nowak G. (1993) Isolation and chromatography of 15-deoxyrepin and 25 other sesquiterpene lactones from Centaurea bella trautv, Acta Societatis Botinacorum Poloniae , 62: 33-6.

[6] Christensen L.P., Lam J. (1991) Acetylenes and other constituents from Centaurea species, Phytochemistry, 30: 3289-92.

[7] Tekeli Y., Zengin G., Aktumsek A., Sezgin M. (2017) Comparison of the fatty acid compositions of Six Centaurea species. Chemistry of Natural Compounds , 49(3): 496-8.

[8] Lazari D., Skaltsa H., Constantinidis T. (2000) Volatile constituents of Centaurea pelia DC., C-thessala Hausskn. subsp drakiensis (Freyn \& Sint.) Georg. and C-zuccariniana DC. from Greece, Flavour and Fragnance Journal, 15: 7-11.

[9] Zengin G., Guler G.O., Cakmak Y.S., Aktumsek A. (2011) Antioxidant capacity and fatty acid profile of Centaurea kotschyi (Boiss. \&amp; Heldr.) Hayek var. (Boiss.) Wagenitz from Turkey, Grasas y Aceites, 62(1): 90-5.

[10] Akbar E., Abdolhossein R., Mohammad T.A., Nasrin M.,Shiva M. and Hamzeh A. (2006) Composition of the essential oils of Xanthium strumarium L. and Centaurea solstitalis L. from Iran, Journal of Essential Oil Research, 18: 427-9.

[11]Lazari D., Skaltsa H., Constantinidis T. (1999) Volatile constituents of Centaurea raphanina Sm. subsp mixta (DC.) Runemark and C. spruneri Boiss. \& Heldr. (Asteraceae), growing wild in Greece, Flavour and Fragnance Journal, 14: 415-8.

[12] Ertas A., Gören A.C., Boga M., Demirci S., Kolak U. (2014) Chemical composition of the essential oils of three Centaurea species growing wild in Anatolia and their anticholinesterase activities, Journal of Essential Oil Bearing Plants, 17: 922-6. 